\title{
Perception of late effects among long-term survivors after haematopoietic stem cell transplantation: Descriptive analysis and validation of the Brief Illness Perception Questionnaire. A sub-study of the PROVIVO study
}

\author{
Sabine Valenta ${ }^{\text {a, b}}$, Sabina De Geest ${ }^{\text {a, c }}{ }^{\text {, Katharina Fierz }}{ }^{\text {a }}$, Sonja Beckmann ${ }^{\text {a, }}{ }^{\text {, }}$, \\ Jörg Halter ${ }^{\mathrm{b}}$, Urs Schanz ${ }^{\mathrm{e}}$, Gayathri Nair ${ }^{\mathrm{b}, \mathrm{e}}$, Monika Kirsch ${ }^{\mathrm{f}, *}$ \\ a Nursing Science (INS), Department Public Health (DPH), University of Basel, Switzerland \\ ${ }^{\mathrm{b}}$ Department of Haematology, University Hospital Basel, Switzerland \\ ${ }^{\mathrm{c}}$ Centre for Health Services and Nursing Research, KU Leuven, Belgium \\ ${ }^{\mathrm{d}}$ Department of Abdomen-Metabolism, University Hospital Zurich, Switzerland \\ e Department of Haematology, University Hospital Zurich, Switzerland \\ ${ }^{\mathrm{f}}$ Department of Anaesthesiology / Pain Service, University Hospital Basel, Switzerland
}

\section{A R T I C L E I N F O}

\section{Article history:}

Received 15 October 2016

Received in revised form

24 December 2016

Accepted 16 January 2017

\section{Keywords:}

Haematopoietic stem cell transplantation Late effects

Long-term survivorship

Validity

AERA-Standards

German Brief Illness Perception Questionnaire PROVIVO study

\begin{abstract}
A B S T R A C T
Purpose: To give a first description of the perception of late effects among long-term survivors after Allogeneic Haematopoietic Stem Cell Transplantation (HSCT) and to validate the German Brief Illness Perception Questionnaire (BIPQ).

Methods: This is a secondary analysis of data from the cross-sectional, mixed-method PROVIVO study, which included 376 survivors from two Swiss HSCT-centres. First, we analysed the sample characteristics and the distribution for each BIPQ item. Secondly, we tested three validity types following the American Educational Research Association (AERA)Standards: content validity indices (CVIs) were assessed based on an expert survey $(n=9)$. A confirmatory factor analysis (CFA) explored the internal structure, and correlations tested the validity in relations to other variables including data from the Hospital Anxiety and Depression Scale (HADS), the number and burden of late effects and clinical variables.

Results: In total, 319 HSCT recipients returned completed BIPQs. For this sample, the most feared threat for post-transplant life was long lasting late effects (median $=8 / 10$ ). The expert-survey revealed an overall acceptable CVI $(0.82)$, three items-on personal control, treatment control and causal representation-yielded low CVIs $(<.78)$. The CFA confirmed that the BIPQ fits the underlying construct, the Common-Sense Model $(\mathrm{CSM})\left(\chi^{2}(\mathrm{df})=956.321, \mathrm{p}=0.00\right)$. The HADS-scores correlated strongly with the item emotional representation $(r=0.648 ; r=0.656)$.

Conclusion: According to its overall content validity, the German BIPQ is a promising instrument to gain deeper insights into patients' perceptions of HSCT late effects. However, as three items revealed potential problems, improvements and adaptions in translation are therefore required. Following these revisions, validity evidence should be re-examined through an in-depth patient survey.
\end{abstract}

๑) 2017 Elsevier Ltd. All rights reserved.

\section{Introduction}

Allogeneic Haematopoietic Stem Cell Transplantation (HSCT) is an intensive treatment for high-risk malignant as well as specific

\footnotetext{
* Corresponding author. Advanced Practice Nurse (APN), Anaesthesiology / Pain Service, University Hospital of Basel, Spitalstrasse 21, CH-4031 Basel, Switzerland.

E-mail address: Monika.Kirsch@usb.ch (M. Kirsch).
}

life-threatening non-malignant haematological disorders and certain genetic diseases (Tichelli et al., 2012). Although it is a curative treatment, long-term survivors have an increased risk of developing various adverse side effects, also known as late effects. Because of their long-lasting character, late effects can be seen as chronic illness conditions (Majhail and Rizzo, 2013; Stein et al., 2008).

In addition to malignant late effects, e.g., solid tumours and 
secondary haematological diseases, HSCT recipients can also suffer from non-malignant physical and psychological sequelae. Common physical late effects include ocular, pulmonary, cardiac, endocrine, skeletal, gastrointestinal and hepatic dysfunction (Gratwohl et al., 2010; Socié et al., 2003). Among allogeneic HSCT recipients, though, the major late complication is chronic Graft-versus-HostDisease (cGvHD), where donor T lymphocytes attack the patient's organs. For the period from 2004 to 2007, the Center for International Blood and Marrow Transplant Research reported a 36\% incidence of cGvHD among HSCT recipients (Arai et al., 2015). Severe forms of cGvHD can significantly impact a patient's overall health status, especially regarding functional impairment, activity limitation, and pain (Ferrara et al., 2009; Majhail and Rizzo, 2013). Additionally, the emotional burden can be immense: prolonged psychological distress, including significant levels of anxiety and depression, is associated with worse post-transplant physical health (Cooke et al., 2009; Syrjala et al., 2005). Patients already suffering from high numbers of late effects are particularly distressed by the resulting exacerbation of psychological and physical symptoms (Bhatia, 2011; Mosher et al., 2009).

In order to improve HSCT survivors' health-related quality of life, it is important to enhance early detection of late affects (Khera et al., 2011). Until now, the standard source of data concerning post-HSCT late effects has been clinicians' reports. However, this measure tends to underestimate the incidence, severity, and distress of patients' perceived symptoms (Xiao et al., 2013). Therefore, over the past decade, patient reported outcomes (PROs) have been increasingly applied. As an umbrella concept, PROs include parameters related to patients' illness perceptions and their self-reported health status (FDA, 2006).

Patients' perceptions of illness conditions encompass their beliefs about their health problems and associated symptoms (Petrie and Weinman, 2012). In this study, we rely on the definition of illness representation set forth in the Common-Sense Model (CSM) of self-regulatory theory. As Fig. 1 illustrates, the CSM assumes that patients assess their health conditions based on cognitive and emotional representations, adopt coping behaviours, estimate their efficacy, and finally appraise the outcomes (Cameron and Leventhal, 2003; Leventhal et al., 1980).

Early research identified four dimensions of cognitive representation that can be adapted to the experience of late effects as chronic health conditions (Leventhal et al., 1984): perceived consequences of outcomes; beliefs about the timeline (duration) of late effects; the identity (label) associated with each late effect; and causal reasons for late effects. Emotional representation is reflected in the patient's concerns. Representations of coping procedures include controllability, i.e., regarding regulation of personal and treatment risks and benefits, as well as the coherence of the health threat (Broadbent et al., 2006; Leventhal et al., 2003).

So far, it is unknown how patients perceive post-HSCT late effects. By integrating the individual perceptions of a symptom or illness, the self-regulatory theory of health threat cognition and behaviour provides an appropriate basis to approach this question (Leventhal et al., 1998). Based on the CSM of self-regulatory theory, the Brief Illness Perception Questionnaire (BIPQ) provides an appropriate PRO-measurement tool (Broadbent et al., 2006). Since its publication in 2006, the questionnaire has been widely used in populations suffering from various illness states. However, few studies have applied the BIPQ to cancer patients, and no studies have yet applied it to HSCT recipients. Evidence suggests that patients' positive perceptions of their disease and side effects accompany a clearer understanding of their illness and enhanced self-management (Zivkovic et al., 2012). This sub-study of the PROVIVO study was the first to administer the German version of the BIPQ in long-term survivors (Kirsch et al., 2015).
Few studies have tested the validity of the BIPQ. This is problematic, given the fact that exploring the reliability and validity of a measurement tool is a necessary precondition for a sound interpretation of test scores (AERA et al., 2014; Frost et al., 2007). Exploring the content validity of the Dutch BIPQ in a "think-aloud study," Van Oort et al. (2011) identified potential misunderstandings in patients attending preoperative physiotherapy exercise sessions. The BIPQ items on identity, personal control, illness coherence, and causal representation revealed the most difficulties. Another Dutch semantic evaluation including physiotherapists and students rated the content validity as acceptable and showed significant correlations regarding four BIPQ-items $(p<0.05)$ (De Raaij et al., 2012). In addition, Broadbent and colleagues confirmed the English BIPQ's strong concurrent $(p<0.001)$ and predictive validity $(\mathrm{p}=0.03)$ in renal failure, diabetes, and asthma samples (Broadbent et al., 2006). Until this study, the German BIPQ had never been validated. Therefore, the purpose of this study was to give a first description of the perception of late effects among long-term survivors after HSCT and to explore the validity of the German BIPQ.

\section{Methods}

\subsection{Design, sample, and setting}

This is a sub-study of the cross-sectional, mixed-method PROVIVO study. Details of that study's methods have been published elsewhere (Kirsch et al., 2015; NCT01275535). In brief, data were collected from November 2011 to October 2012 from a convenience sample of 376 patients attending the University Hospitals Basel and Zurich outpatient clinics following HSCT. Ethical approval was provided by the ethics committees of Beider Basel (the Cantons of Basel-Stadt and Basel-Land) (EKBB) and Zurich (KEK Zürich). Participants had received an allogeneic HSCT more than one year before, were 18 years or older, and were able to understand and read German. Participants were excluded if they suffered from psychiatric illness, illiteracy, or terminal illness, or were currently hospitalized for acute care. Before receiving the BIPQ to complete, patients were asked whether they were suffering from any late effects ("yes or no"). Only participants suffering from some form of late effects (marked with "yes") and who answered at least seven of the nine BIPQ items were included in our analysis.

\subsection{Variables and measurement}

\subsubsection{Patient reported outcomes}

The Brief Illness Perception Questionnaire (BIPQ) assesses respondents' cognitive and emotional illness representation of any health condition based on the CSM of self-regulatory theory (Broadbent et al., 2006; Leventhal et al., 1998). The BIPQ was developed on the basis of the Illness Perception Questionnaire (IPQ). A revised and extended version of the questionnaire (IPQ-R) includes more than 80 items on a multifactorial Likert-type scale approach (Moss-Morris et al., 2002; Weinman et al., 1996). The original 9-item BIPQ uses a single-item scale approach on a continuous linear scale. Items 1 to 8 are interval scaled, applying 11-point (0-10) Likert-type scales for consequences, timeline, personal control, treatment control, identity, coherence, concern, and emotions. Higher scores reflect more threatened perceptions of late effects.

Item 9 is an open question asking the respondent to list the three most important reasons for developing late effects. The general version of the questionnaire uses the word "illness", which must be replaced in each item with the name of the examined health condition - in this case "late effects" 


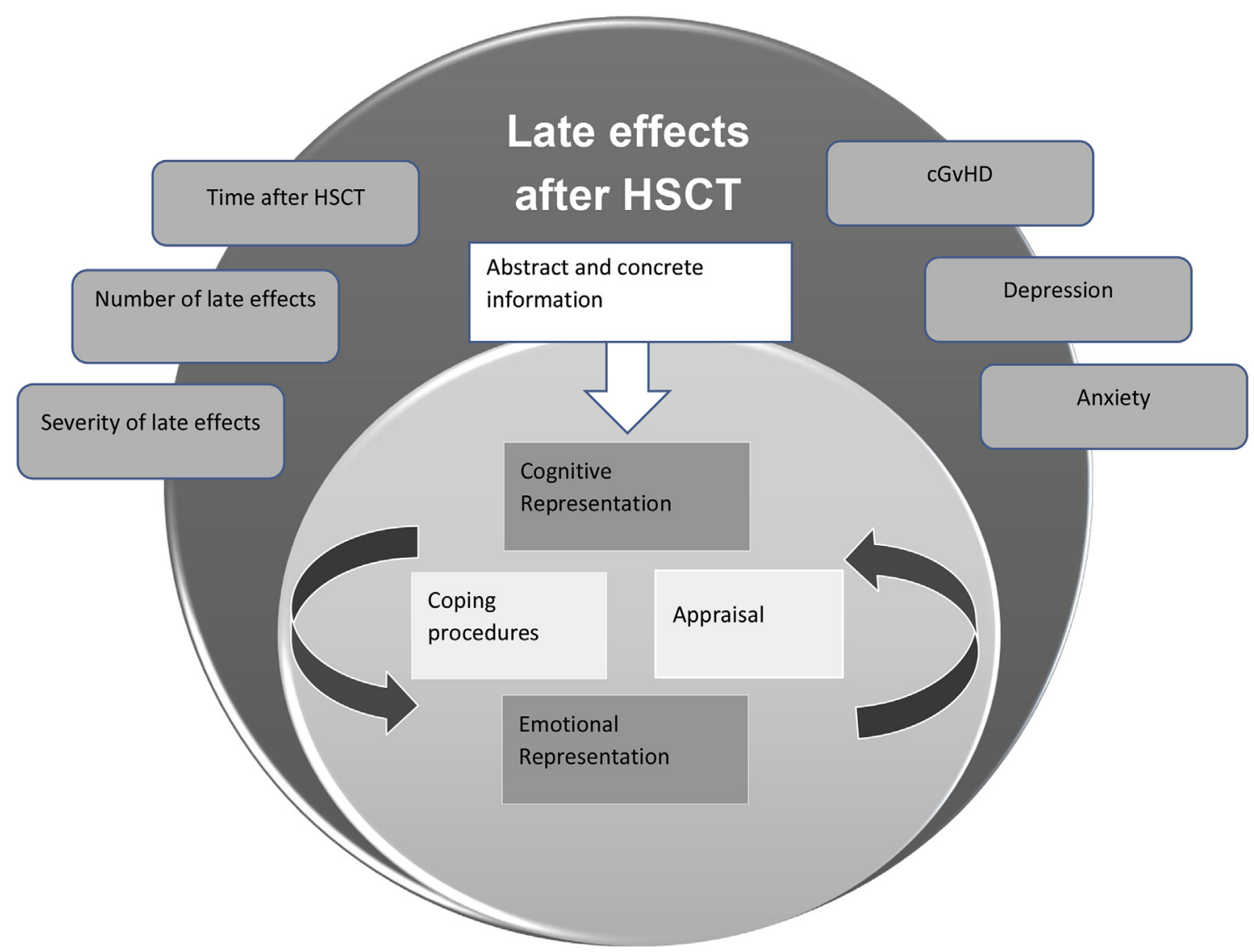

Note. The Common-Sense Model (CSM) of Leventhal's self-regulatory theory exemplified in the context of late effects after HSCT (Cameron and Leventhal, 2003).

Fig. 1. The Common-Sense Model (CSM) of Leventhal's self-regulatory theory.

(German = "Spätfolgen"). So far, the BIPQ has been translated from the original English into 24 different language versions, all of which are available on the Illness Perception Questionnaire Website (Weinman et al., 2012).

The Hospital Anxiety and Depression Scale (HADS). Anxiety and depression symptomatology were assessed via the HADS, which consists of two subscales and 14 items using 4-point Likert-type scales (Zigmond and Snaith, 1983). The two subscales, one measuring anxiety, the other depressive symptomatology, consist of seven items each. Scores of 11 or more on either subscale indicate significant psychological morbidity; those between 8 and 10 represent borderline cases; and those below 8 are clinically insignificant. Both subscales can be interpreted independently (Bjelland et al., 2002).

\subsubsection{Clinical data}

Clinical data provided by clinicians on each patient include years after transplantation, grade of cGvHD according to the National Health Institute $(\mathrm{NIH})$ criteria (none, mild, moderate, severe) (Pavletic et al., 2006), and a Karnofsky Performance Status Scale (KPS) index. Based on a criteria related performance index of physical ability, the KPS index rates individual health and wellbeing from $100 \%$ (normal function) to $10 \%$ (moribund) (Mor et al., 1984).

Observable late effects rated by the physician. In accordance with the Common Terminology Criteria for Adverse Events (CTCAE) version 3.0 ( $\mathrm{NCI}, 2006)$, physicians assessed the cumulative incidence and severity of patients' late effects at the time of the annual check-up. Thirteen general late effects affecting various organs were rated according to their occurrence and severity: thyroid dysfunction, osteoporosis, osteonecrosis, cardiac dysfunction, pulmonary function disorder, renal and liver dysfunction, ocular problems, hearing problems, dental/mouth problems, iron overload, neurotoxicity, neurocognitive disorders, and secondary malignancy.

The cumulative number of late effects per patient was assessed, ranging from 0 to 13 . The severity of each was rated from 0 (nonexistent) to 4 (disabling or life-threatening), resulting in a possible total score of $0-52$. Considering the number and severity of late effects, the CTCAE specifies five categories of burden of late effects: none (no late effects as present); mild (late effects of severity grade 1 only; $\leq 3$ late effects); moderate (one or more late effects grade 2; or 4-6 late effects); severe (one or more late effects grade 3 ; or $>7$ late effects) and disabling (one or more late effects grade 4 irrespective of number of late effects).

\subsection{Statistical analysis}

All analyses were performed using IBM SPSS Statistics, version 22.

Aim 1: descriptive statistics. We begin with an overview, using descriptive statistics, of the sample's characteristics and each BIPQ item's distribution. Following the BIPQ analysis instructions, we reversed the scores of items 3,4 and 7 so that they measured in the same direction as the others. For the open question on causal representation (item 9), we followed Broadbent's advice and 
categorized the patients' statements as pre-treatment, psychological burden or physical reasons (Broadbent, 2006).

Aim 2: psychometric testing of the BIPQ. Validity testing of the BIPQ followed the American Educational Research Association (AERA) Standards (AERA et al., 2014). Thus, we tested three distinct aspects of validity: test content, internal structure, and relations to other variables. Evidence based on response process and consequences of testing were not addressed in the present study, since these validity types are more relevant in the context of evaluating educational and employment questionnaires (AERA et al., 2014). All questions on research $(\mathrm{R})$, hypotheses $(\mathrm{H})$, and the thorough assessment of the validity evidence regarding the BIPQ can be found in Table 1.

Evidence based on test content ( $\mathrm{R} 1 \& 2$, Table 1 ) was assessed using input from an interdisciplinary group of experts consisting of nine nurses and physicians from three German and two Swiss transplantation centres, each of whom had worked at least two years in post-HSCT patient follow-up care. On 4-point Likert-type scales ranging from 1 (not comprehensible) to 4 (highly comprehensible), these experts rated the comprehensibility of each BIPQ item. Based on their ratings, we calculated a content validity index for each item (I-CVI) and an overall scale-content validity index (S$\mathrm{CVI}$ ) for the entire questionnaire. The I-CVI was computed as the number of experts giving a rating of either 3 or 4 (dichotomizing the ordinal scale into relevant and not relevant), divided by the total number of experts. The S-CVI was computed using the average approach (S-CVI/Ave) for all items on the scale. Therefore, we summed up the I-CVI and then divided it by the number of items. An I-CVI of $\geq 0.78$ and an S-CVI $\geq 0.80$ can be regarded as satisfactory (Polit and Beck, 2006; Polit et al., 2007). The experts were also asked for feedback and suggestions for improvement of the questionnaire. In addition to the expert survey, we analysed the number of missing values for each BIPQ item.

Evidence based on internal structure (R3, Table 1 ) required a confirmatory factor analysis (CFA). To produce this, we tested whether the internal components of the BIPQ fit the underlying construct of the Common-Sense Model (CSM) of self-regulatory theory. All eight interval-scored BIPQ-items were included in this analysis. Following the CSM, we applied a two-factor-model: one factor depicted the cognitive and emotional representation; the other the coping procedures. Considering Kaiser's rule, we included only factors with eigenvalues greater than 1 in our interpretations (Fabrigar et al., 1999). To test our sampling adequacy, we used the Kaiser-Meyer-Olkin Index, which should be greater than 0.5 (Kaiser and Rice, 1974). Analysing the factorability of the correlation matrix required Bartlett's test of sphericity $(\mathrm{p}<0.05)$. We considered loading factors greater than 0.4 as acceptable (Field, 2009).

As expressed in hypotheses 1 to 5 (Table 1), evidence based on relations to other variables was assessed to explore criterion-related validity. The mean subscale scores of the German BIPQ were therefore correlated with other clinical variables acknowledged for their relationships to late effects: HADS score, cGvHD severity, Karnofsky Performance Status Scale (KPS) index, and the number and burden of late effects. Depending on the distribution characteristics, we estimated Pearson's $r$ or Spearman's $\rho$ (two-tailedtests).

\section{Results}

\subsection{Study sample}

Of the 376 patients participating in the PROVIVO study, 319 (85\%) fulfilled the criteria for inclusion in our analysis, i.e., they reported late effects and completed at least 7 of the 9 BIPQ items (Fig. 2). Table 2 summarizes the participants' characteristics: patients were predominantly male (57.1\%), with a mean age of 50.2 years $(\mathrm{SD}=12.9)$, and a median post-SCT follow-up period of 7.3 years $(I Q R=8.9)$. Nearly half $(46.7 \%)$ had received a HSCT against acute myeloid (31.7\%) or acute lymphatic (15.0\%) leukaemia. Most experienced either no cGvHD (51.1\%) or a mild form (28.5\%), and $77.1 \%$ were highly functional (KPS index scores $\geq 90 \%$ ). With respect to HADS scores, 6.3\% showed high anxiety levels, i.e. their anxiety subscale scores were above the cut-off-point of 8 . Regarding the depression subscale, $4.1 \%$ reported depressive symptoms. Most experienced a mild to moderate (47.6\%) burden of late effects. Two participants suffered from disabling late effect burdens, impairing their quality of life dramatically.

\subsection{Descriptive analysis of the BIPQ-items}

Table 3 displays the average scores of the BIPQ items. The second item, timeline, showed the highest score, meaning that patients perceived their late effects as long-term threat (median $=8$, $\mathrm{IQR}=7$ ). The items on consequences and identity (items 1 and 5: median $=3, \mathrm{IQR}=4$ ), comprehension (item 7: median $2, \mathrm{IQR}=4$ ) and emotional representation (item 8 : median $=2, \mathrm{IQR}=5$ ) received relatively low scores. The items on personal and treatment control (item 3 and 4) and on concerns (item 6) received moderate scores (median $=5, \mathrm{IQR}=5$ ) indicating that participants were concerned about their late effects and their controllability.

Regarding the categorization of item 9 (the open question), respondents perceived medication intake (54\%), chemotherapy (45\%) and irradiation (41\%) as the most important reasons for developing late effects. Also, patients perceived psychological burdens (36\%), the HSCT (23\%) and cGvHD (17\%) as further reasons for developing post-HSCT late effects (see Fig. 3 ).

\subsection{Validity testing}

\subsubsection{Content validity}

The BIPQ's S-CVI/Ave was acceptable, at 0.82 . With respect to the I-CVIs, six items-consequences, timeline, identity, concerns, comprehension, and emotional representation-showed high values ranging from 0.78 to 1.0 (possible range: $0.0-1.0$ ). However, the remaining three - personal control, treatment control, and causal representation - yielded I-CVIs below the recommended minimum of 0.78 (see Table 3 ).

According to our experts' feedback, some items would benefit from small adaptions: concerning the question on the duration of late effects (item 2, timeline), four experts noted that one more time specification would improve this item's comprehensibility. With respect to controllability (items 3 and 4), five experts mentioned that the term "control" invites misunderstandings. Suggested improvements included replacing "control" with "influence" or "manage" since some late effects like cGvHD are difficult to put under control (German: ,, beeinflussen” oder ,, verbessern”). Five experts also indicated that item 7, comprehension of late effects, requires further explanation. Two experts suggested the following amendments: "How well do you feel the treatment of your late effects is explained to you?" (German: "Wie gut fühlen Sie sich über die Behandlung der Spätfolgen aufgeklärt?"). Item 8, on emotional representation, was described as a "confusing question," as it includes only negative feelings. It was suggested that simplification would promote understanding: "How strongly are your feelings influenced by your late effects?" (German: "Wie stark sind Ihre Gefühle durch die Spätfolgen beeinflusst?"). To promote a fuller grasp of causal representation (item 9), two experts suggested shortening the question and inserting examples such as "medication or therapy."

For the interval-scaled items (1-8), a missing value analysis yielded comparatively low values (range: $0 \%-5.6 \%$, see Table 3 ). Regarding causal representation (item 9), 22\% of respondents 
Table 1

Research questions $(\mathrm{R})$ and hypotheses $(\mathrm{H})$ of the validation study.

\begin{tabular}{|c|c|c|}
\hline Lines of validity evidence & Research question $(\mathrm{R})$ or hypotheses $(\mathrm{H})$ & Analysis \\
\hline \multirow[t]{2}{*}{$\begin{array}{l}\text { Evidence based on test } \\
\text { content }\end{array}$} & R1: Are the BIPQ items relevant and appropriate? & $\begin{array}{l}\text { Expert survey to assess the Content Validity } \\
\text { Index }(\mathrm{CVI})\end{array}$ \\
\hline & R2: Are the BIPQ items clear and easy to understand? & Missing value analysis \\
\hline $\begin{array}{l}\text { Evidence based on } \\
\text { internal structure }\end{array}$ & R3: Do the internal components of the BIPQ fit the defined construct? & Confirmatory Factor Analysis (CFA) \\
\hline \multirow[t]{5}{*}{$\begin{array}{l}\text { Evidence based on } \\
\text { relations to other } \\
\text { variables }\end{array}$} & $\begin{array}{l}\text { H1: Patients with anxiety and/or depression report a higher degree of consequences, } \\
\text { chronic timeline, identity, concern and emotional representations of late effects } \\
\text { (Gruber et al., 2003; Mosher et al., 2009). }\end{array}$ & $\begin{array}{l}\text { Estimating correlations between BIPQ items } \\
1-8 \text { and corresponding variables from the } \\
\text { PROVIVO study }\end{array}$ \\
\hline & $\begin{array}{l}\text { H2: A higher number of late effects is associated with a higher grade of emotional } \\
\text { and cognitive representation (Pallua et al., 2010). }\end{array}$ & Anxiety \& depression (HADS) \\
\hline & $\begin{array}{l}\text { H3: A higher burden of late effects indicates higher reporting on cognitive and } \\
\text { emotional representations as well as lower perceived controllability of late effects } \\
\text { (Leventhal et al., 1998). }\end{array}$ & Severity of cGvHD (Grade $0-4$ ) \\
\hline & H4: Higher severity of cGvHD is associated with higher ratings for cognitive and & Functional status (Karnofsky Performance \\
\hline & $\begin{array}{l}\text { H5: A lower score of the Karnofsky Performance Status Scale Index is associated } \\
\text { with higher cognitive and emotional representation of late effects (Sorror et al., } \\
\text { 2008). }\end{array}$ & Number and burden of late effects (CTCAE) \\
\hline
\end{tabular}

Note. Tabulated research questions and hypotheses to test the lines of validity evidence based on the AERA-Standards for psychometric testing (AERA et al., 2014).

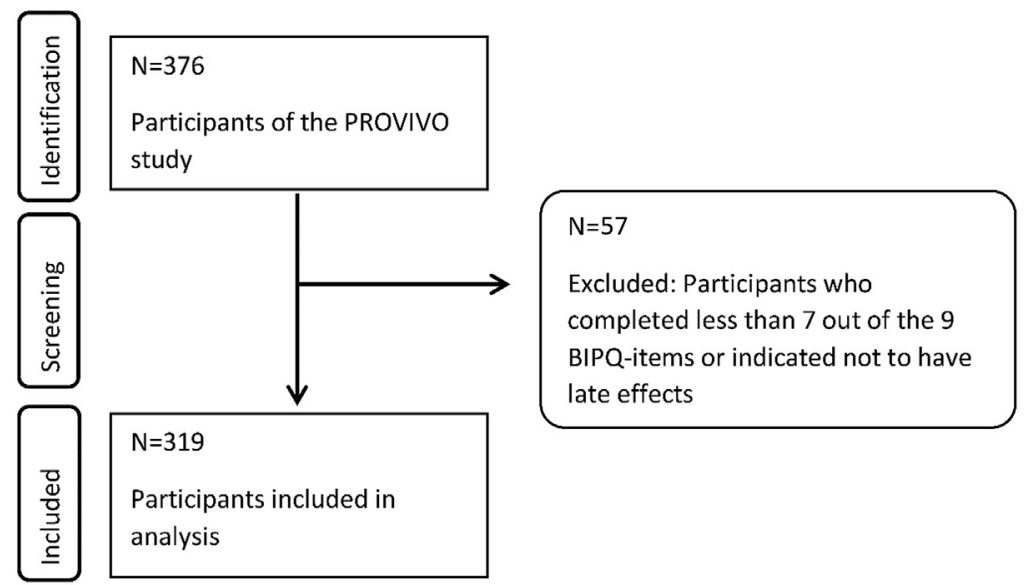

Note. Subsample from the PROVIVO study: patients indicating to suffer from any form of late effects or who completed at least 7 out of the 9 BIPQ-items.

Fig. 2. Flow Chart of included participants.

specified no reason for developing late effects.

\subsubsection{Internal structure}

The Kaiser-Meyer-Olkin measure of sampling adequacy (0.77) and Bartlett's test of sphericity $\left(\chi^{2}=956.321, p=0.00\right)$ indicated that the data were appropriate to conduct a CFA. The results of the CFA were consistent with the CSM's underlying concept: all items loaded above the recommended minimum level $(>0.4)$ on the two expected factors, i.e., (1) cognitive and emotional representation and (2) coping procedures. These two factors accounted for $62.67 \%$ of the total variance.

Factor loadings ranged from 0.498 to 0.906 (see Fig. 4). All items loaded strongly and consistently on the two expected factors. The only exception was timeline (item 2 ) which cross-loads positively on the first (0.498) and negatively on the second (-0.378). Nevertheless, the internal components of the BIPQ fit the underlying construct of the CSM very well.

\subsubsection{Relations to other variables}

Table 4 shows positive correlations between the respondents' anxiety and depression scores and the BIPQ consequences, timeline, identity, concern, and emotional representation items. As hypothesized ( $\mathrm{H} 1)$, emotional representation correlated strongly with scores for anxiety $(r=0.648, p<0.01)$ and depression $(\mathrm{r}=0.656, \mathrm{p}<0.01)$. However, regarding the second hypothesis (H2), a high number of late effects correlated only marginally with consequences $(\mathrm{r}=0.214, \mathrm{p}<0.01)$, identity $(\mathrm{r}=0.219, \mathrm{p}<0.01)$, and concerns $(\mathrm{r}=0.154, \mathrm{p}<0.01)$. As can be seen in Table 4, our third hypothesis (H3) also had limited support: we found low correlations between burden of late effects and the corresponding BIPQ items; and contrary to the expectations reflected in the fourth $(\mathrm{H} 4)$ and fifth (H5) hypotheses, CGvHD scores and the KPS Index showed only weak to moderate correlations with the BIPQ items on consequences, identity, concern and emotional representations (see Table 4).

\section{Discussion}

This was both the first study to evaluate the German BIPQ in relation to long-term survivors' perceptions of post-HSCT late effects and the first to measure its psychometric properties following the new AERA standards (AERA et al., 2014). Our analyses indicated that HSCT recipients perceive long-lasting late effects-and the accompanying suffering-as their greatest therapy-related threat. 
Table 2

Characteristics of the study sample $(n=319)$.

\begin{tabular}{|c|c|}
\hline Characteristic & Total sample, $\mathrm{n}=319$ \\
\hline Gender; female, n (\%) & $137(42.9)$ \\
\hline Age in years, median (SD; range) & $50.2(12.9 ; 19-76$ years $)$ \\
\hline Years after HSCT, median (IQR; range) & $7.3(8.9 ; 1-33$ years $)$ \\
\hline \multicolumn{2}{|l|}{ Diagnosis, $\mathrm{n}(\%)$} \\
\hline AML & $101(31.7)$ \\
\hline ALL & $48(15.0)$ \\
\hline CML & $52(16.3)$ \\
\hline CLL & $12(3.8)$ \\
\hline Plasma Cell disorder & $17(5.3)$ \\
\hline Hodgkin or Non-Hodgkin lymphoma & 38 (11.9) \\
\hline Myelodysplastic syndrome & $24(7.5)$ \\
\hline Myeloproliferative syndrome & $10(3.1)$ \\
\hline Non-malignant haematologic disease & $17(5.3)$ \\
\hline \multicolumn{2}{|l|}{ Chronic GvHD ${ }^{\mathrm{a}}$, n (\%) } \\
\hline None & $163(51.1)$ \\
\hline Mild & $91(28.5)$ \\
\hline Moderate & $35(11.0)$ \\
\hline Severe & $11(3.4)$ \\
\hline Not documented & $19(6.0)$ \\
\hline \multicolumn{2}{|l|}{ KPS Index ${ }^{\mathrm{b}}, \mathrm{n}(\%)$} \\
\hline $100 \%-90 \%$ & $246(77.1)$ \\
\hline$<90 \%-80 \%$ & $31(9.7)$ \\
\hline$<80 \%$ & $19(6.0)$ \\
\hline Not documented & $23(7.2)$ \\
\hline \multicolumn{2}{|l|}{ Anxiety $^{\mathrm{c}}, \mathrm{n}(\%)$} \\
\hline No anxiety-borderline & $299(93.7)$ \\
\hline Indication of anxiety & $20(6.3)$ \\
\hline \multicolumn{2}{|l|}{ Depression $^{\mathrm{c}}, \mathrm{n}(\%)$} \\
\hline No depression-borderline & 305 (95.9) \\
\hline Indication of depression & $13(4.1)$ \\
\hline \multicolumn{2}{|l|}{ Observable late effects ${ }^{\mathrm{d}}, \mathrm{n}(\%)$} \\
\hline Number of late effects, median & 2.0 \\
\hline \multicolumn{2}{|l|}{ Burden of late effects } \\
\hline none & $64(20.1)$ \\
\hline mild & $84(26.3)$ \\
\hline moderate & $68(21.3)$ \\
\hline severe & $101(31.7)$ \\
\hline disabling & $2(0.6)$ \\
\hline
\end{tabular}

Note. Selected characteristics of the HSCT survivor sample focusing on variables of this sub-study.

Abbreviations $\mathrm{IQR}=$ Interquartile Range, AML = Acute Myeloid Leukaemia, $\mathrm{ALL}=$ Acute Lymphatic Leukaemia, $\mathrm{CML}=$ Chronic Myeloid Leukaemia, $\mathrm{CLL}=$ Chronic Lymphatic Leukaemia, cGvHD = chronic Graft-versus-Host-Disease, KPS = Karnofsky Performance Status Scale.

a Chronic GvHD was rated by the physician according to the cGvHD grading scheme recommended by the National Institutes of Health consensus development project on criteria for clinical trials in cGvHD (Pavletic et al., 2006).

b Karnofsky Performance Status Scale (KPS) Index of physical ability (Mor et al., 1984).

c Anxiety and depression measured by the Hospital Anxiety and Depression Scale (HADS) (Bjelland et al., 2002).

d Observable late effects rated by the physician, CTCAE version 3.0 (NCI, 2006).

Evaluated by clinical experts, our instrument showed good content validity and gave some hints for improvement of the German translation. Furthermore, a CFA indicated that the internal components of the BIPQ fit the underlying construct of the CommonSense Model of self-regulatory theory. Regarding relations to other variables, along with the HADS scores, the number and burden of late effects correlated significantly with individual BIPQ items. However, the clinical variables, among others, correlated moderately at best with the BIPQ.

\subsection{Descriptive analysis of the BIPQ responses}

The timeline item showed the highest scores (median $=8$, $\mathrm{Q} 1=3, \mathrm{Q} 3=10$ ), indicating that patients recognize the chronic nature of their late effects. The literature indicates that late effects can occur at any time after treatment and may last the remainder of the patient's life (Majhail and Rizzo, 2013). However, compared to the duration of late effects, patients rated concern and emotional representation relatively low, suggesting that many consider their physical constraints manageable (Mosher et al., 2009; Syrjala et al., 2004).

Surprisingly, patients rated consequences low (median: 3), indicating a belief that their late effects would have no serious consequences. They also felt capable of bringing them under personal and treatment control (median: 5). In contrast to these results, the meta-analytic review of the CSM published by Hagger and Orbell (2003) showed that patients with benign chronic disease who emphasized a chronic timeline also typically indicated a lack of controllability, experienced serious consequences, and attributed a strong identity to their health condition.

Our findings in the survivor population might be explained by a so-called "response shift". Patients may adapt their internal standards or values and use this new approach to determine their perceptions of illness burden. Regarding this type of post-HSCT adjustment, supportive care, optimism and flexible expectations are excellent examples of helpful mechanisms and attitudes (Beeken et al., 2011; Sprangers and Schwartz, 1999).

Nearly $50 \%$ of patients indicated the treatment process itself (e.g., chemotherapy, medication, and irradiation) as the most important cause of post-HSCT late effects, which is consistent with the scientific view of their aetiology (Tichelli et al., 2012). Risk factors for developing late post-HSCT complications depend on pretreatment procedures, the details of the conditioning regime, and the use of total body irradiation. Also, while more than a third of respondents (36\%) connected their psychological burden to evolving late effects, the causality is unclear. I.e., questions remain as to whether various post-HSCT late effects arise from psychological burden or the post-HSCT psychological burden intensifies existing late effects. Both may be true. Research indicates both that distressing post-HSCT physical and cognitive side effects accompany psychological burden (Herzberg et al., 2013; Mosher et al., 2009), and that elevated depressive symptoms correlate with reduced physical function and decreased survival in HSCT recipients (Loberiza et al., 2002; Rusiewicz et al., 2008).

\subsection{Validity testing}

\subsubsection{Content validity}

A strong overall content validity index $(0.82)$ confirms that the BIPQ's sample of items is sufficient to represent the construct of interest, i.e., patients' perceptions of post-HSCT late effects. With respect to the $\mathrm{I}-\mathrm{CVI}$, though, the items "personal and treatment control" indicated potential problems: experts reported that these were formulated too vaguely, and that their use of the term "control" could lead to misunderstandings. Previous research has also shown that the "personal and treatment control" items assume that, based on pre-existing knowledge, the respondents' can regulate the risks and benefits of their behaviour (Cameron and Leventhal, 2003). Therefore, as suggested by Van Oort et al. (2011), it was decided that "control" should be replaced with "influence".

Likewise, the "causal representation" items showed a low I-CVI (0.63). They were also missing a high number of patient responses (22\%), indicating potential difficulties in answering. This explanation would support the findings of Van Oort et al. (2011), who illustrated patients' difficulties in answering items on "identity", "comprehension", "control" and "causal representation" of a chronic illness (Van Oort et al., 2011). Again, in accordance with Van Oort et al. (2011), our experts suggested replacing "control" with "influence".

Similarly, the "causal representations"' item (item 9) was improved by reframing the question from "Please list in rank-order 
Table 3

BIPQ-item characteristics.

\begin{tabular}{|c|c|c|c|c|}
\hline BIPQ-items & Missing data (\%) & Mean $(\mathrm{SD})^{\mathrm{a}}$ & $\begin{array}{l}\text { Median } \\
\text { (IQR) }\end{array}$ & I-CVI-Index \\
\hline 1. Consequences & $0 \%$ & $\begin{array}{l}3.45 \\
(3.00)\end{array}$ & $3(4)$ & 0.89 \\
\hline 2. Timeline & $5.6 \%$ & $\begin{array}{l}6.30 \\
(3.80)\end{array}$ & $8(7)$ & 0.89 \\
\hline 3. Personal control & $2.5 \%$ & $\begin{array}{l}5.53 \\
(3.16)\end{array}$ & $5(5)$ & 0.56 \\
\hline 4. Treatment control & $2.5 \%$ & $\begin{array}{l}5.19 \\
(3.41)\end{array}$ & $5(6)$ & 0.56 \\
\hline 5. Identity & $0.3 \%$ & $\begin{array}{l}3.36 \\
(3.01)\end{array}$ & $3(4)$ & 1.00 \\
\hline 6. Concern & $0.3 \%$ & $\begin{array}{l}3.43 \\
(2.94)\end{array}$ & $5(5)$ & 1.00 \\
\hline 7. Comprehension & $1.6 \%$ & $\begin{array}{l}3.08 \\
(2.93)\end{array}$ & $2(4)$ & 0.89 \\
\hline 8. Emotional representation & $0.3 \%$ & $\begin{array}{l}3.91 \\
(2.98)\end{array}$ & $2(5)$ & 0.78 \\
\hline 9. Causal representation & $22 \%$ & not applicable & & 0.63 \\
\hline
\end{tabular}

Note. Descriptive statistics for the individual items of the BIPQ. Frequencies for included participants only ( $\mathrm{n}=319$ ). Item 3 , 4 and 7 were reversed prior to analysis. An I-CVI $\geq 0,78$ is regarded as satisfactory (Polit and Beck, 2006).

Abbreviations: $\mathrm{SD}=$ Standard Deviation, $\mathrm{IQR}=$ Interquartile range, $\mathrm{I}-\mathrm{CVI}=$ Item Content Validity Index.

a Mean scores of BIPQ-items: Higher scores reflect a more threatening view of late effects.

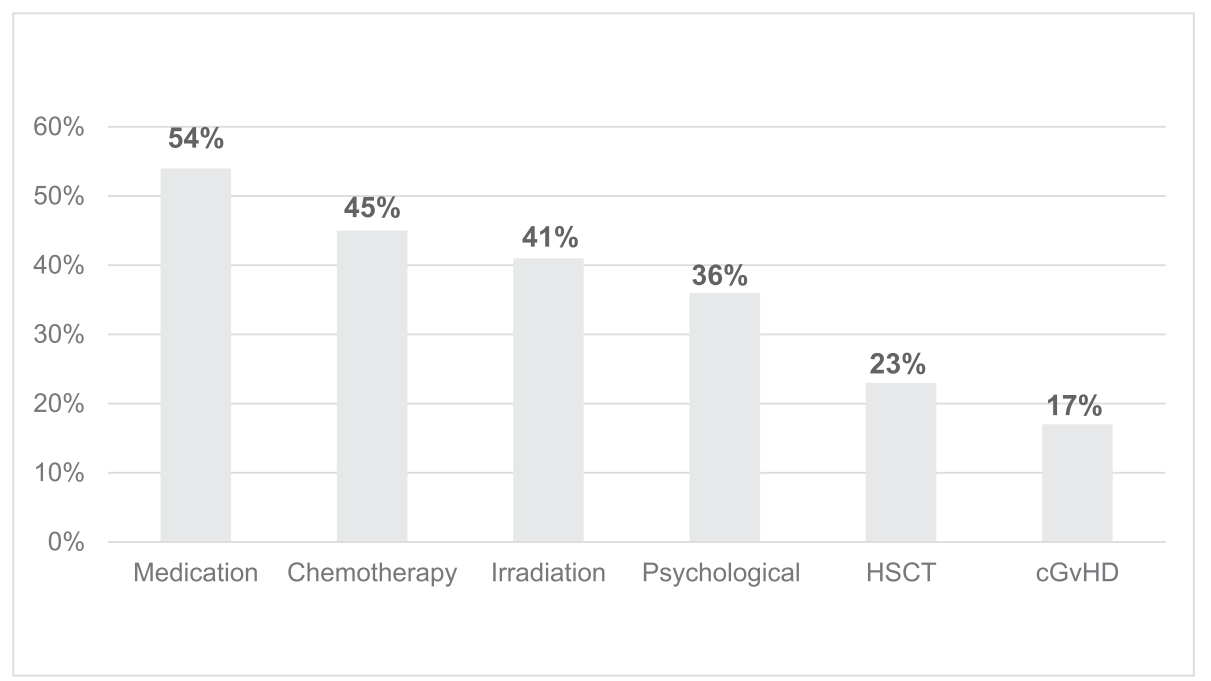

Note. Descriptive statistics of item 9 of the BIPQ, ${ }^{\text {a }}$ frequency for included participants only $(n=319)$.

Abbreviations: HSCT= Hematopoietic Stem Cell Transplantation, cGvHD= chronic Graft-versus-Host-

Disease.

Fig. 3. Patients' reasons for having late effects: Descriptive analysis of BIPQ item 9.

the three most important factors that you believe caused your illness?" to "What do you think caused your illness"? (Van Oort et al., 2011). Such modifications should be guided by cognitive patient debriefing, as it is considered the gold standard for the development and modification of PRO instruments (Cella et al., 2007; Patrick et al., 2011).

\subsubsection{Internal structure}

The CFA revealed that the internal components of the BIPQ fit the underlying construct, which consisted primarily of cognitive and emotional representation, and secondly of coping procedures. The timeline item was an exception as it loaded positively (0.498) on the first and negatively $(-0.378)$ on the second factor. A possible explanation for these factors' cross-loading can be found in the meta-analytic review of the CSM, which showed that, even while patients' perceptions of an illness chronicity can correlate significantly with more cognitive and emotional consequences, they can also correlate with coping strategies such as avoidance and denial (Hagger and Orbell, 2003). For instance, faced with prolonged late effects, e.g., severe cGvHD, the individual can create a cognitive and/or emotional representation based on their current experience of symptoms. At the same time, perceptions of longlasting cGvHD effects can hinder recovery, as patients may lose hope and not try to develop coping strategies or otherwise selfmanage their condition (Hagger and Orbell, 2003; Pallua et al., 2010).

The three items on personal control, treatment control, and comprehension were strongly associated with the second factor, coping procedures. Cameron and Leventhal (2003) also strongly correlated the controllability of a disease-i.e., the patient's sense of empowerment regarding coping behaviours or treatment efficacywith individuals' coping procedures (Hagger and Orbell, 2003). 


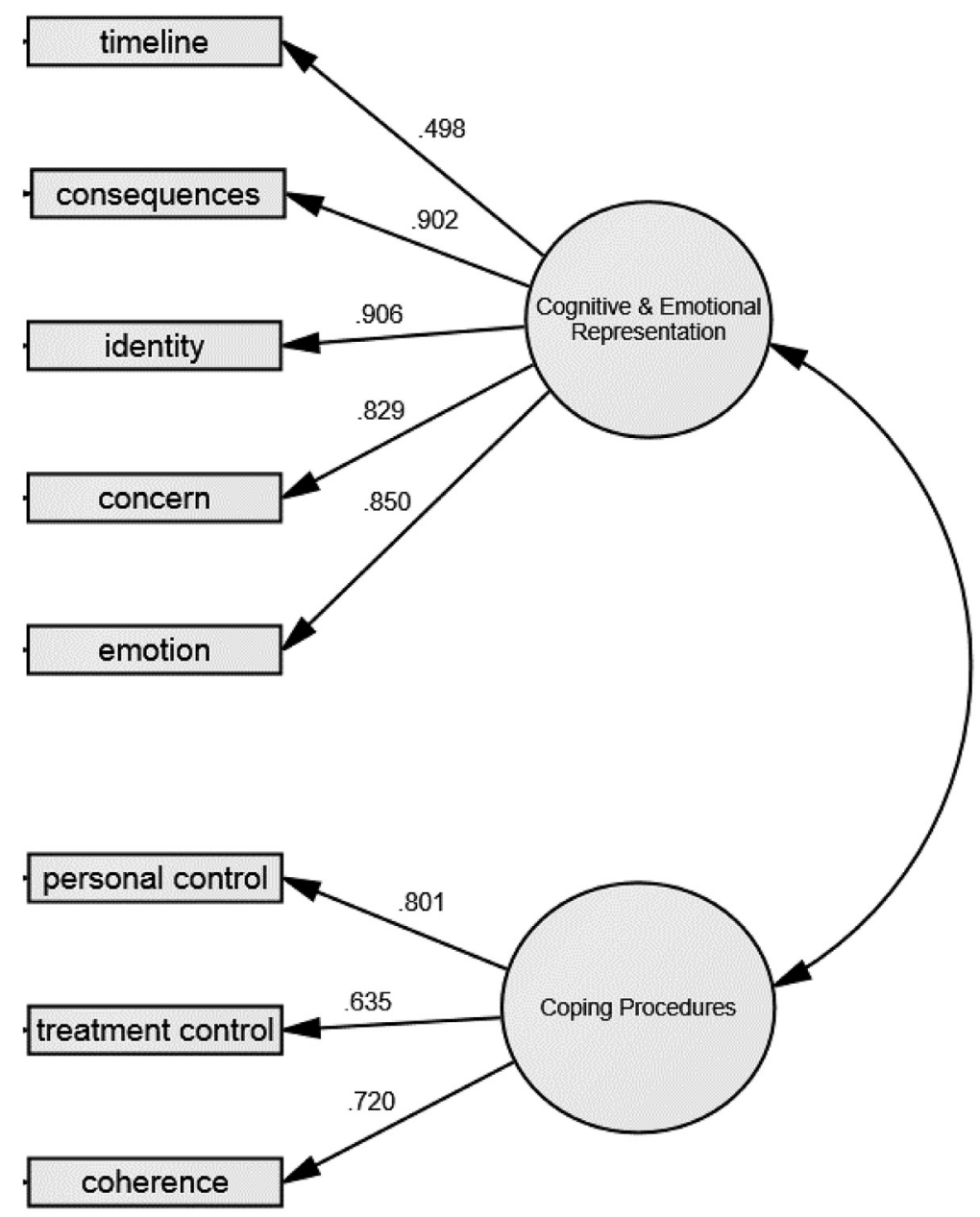

Note. 2-factor model of the confirmatory factor analysis (CFA) including the interval scaled items (1-8) of the BIPQ.

We considered loading factors greater than .4 as acceptable.

Fig. 4. Factor loadings of the Confirmatory Factor Analysis.

Table 4

Relations to other variables: results of calculated coefficients.

\begin{tabular}{|c|c|c|c|c|c|c|}
\hline Variables & HADS-scores & & Late effects & & Clinical variables & \\
\hline $\begin{array}{l}\text { Item } 1-8 \text { of } \\
\text { the BIPQ }\end{array}$ & Anxiety Score & Depression Score & Number of late effects & Burden of late effects & Grade of cGvHD & KPS-Score \\
\hline Consequences & $0.363^{* *}$ & $0.590^{* *}$ & $0.214^{* *}$ & $0.143^{*}$ & $0.256^{* *}$ & $-0.331^{* *}$ \\
\hline Treatment control (reversed scores) & -0.025 & 0.063 & -0.081 & $-0.125^{*}$ & $-0.102^{*}$ & -0.032 \\
\hline Identity & $0.413^{* *}$ & $0.609^{* *}$ & $0.219^{* *}$ & $0.151^{* *}$ & $0.270^{* *}$ & $-0.336^{* *}$ \\
\hline Concerns & $0.522^{* *}$ & $0.539^{* *}$ & $0.154^{* *}$ & $0.124^{*}$ & $0.172^{* *}$ & $-0.171^{* *}$ \\
\hline
\end{tabular}

Note. Asterisks denote statistical significance: ${ }^{* *} \mathrm{p}<0.01$ level, ${ }^{*} \mathrm{p}<0.05$ level. The choice of the correlation coefficient depends on the level of measurement: All correlations between BIPQ-items and HADS-scores and late-effects are Pearson r. Those between BIPQ-items and the clinical variables are Spearman rho. Item 3, 4 and 7 were reversed prior to analysis, $\mathrm{N}=319$.

Abbreviations: HADS= Hospital Anxiety- and -Depression-Scale, cGvHD = chronic Graft-versus-Host-Disease, KPS= Karnofsky Performance Status Scale.

Furthermore, a coherent understanding of illness symptoms contributes to individuals' coping processes by enhancing their selfmanagement abilities (Armoogum et al., 2013; Majhail and Rizzo, 2013). This suggests that long-term post-HSCT survivors who perceive that their late effects are controllable and understandable would rely more on problem-focused cognitive and emotional strategies and social support to cope with their symptom management than would those who find their conditions incomprehensible and perceive that they cannot influence their outcomes (Hagger and Orbell, 2003; Solber Nes et al., 2013). 


\subsubsection{Relations to other variables}

Correlations between the BIPQ and HADS (anxiety and depression) scores supported our first hypothesis (H1): more threatening views of late effects were associated with higher anxiety and depression symptomatology. This correlation supports Hagger and Orbell's finding that individuals suffering from psychological distress perceive more serious consequences, expect their symptoms to continue longer (timeline), and identify more strongly with consequences (Hagger and Orbell, 2003). However, regarding our four remaining hypotheses $(\mathrm{H} 2-\mathrm{H} 5)$, the number and burden of late effects as well as the clinical variables correlated only weakly with the BIPQ items. These weak correlations very likely resulted from the characteristics of our sample: the majority of participants were highly functional (KPS index score $\geq 90 \%$ ), experienced no cGvHD symptoms (51.1\%), and suffered from no serious late effects (67.7\%).

\subsection{Limitations}

The findings of this descriptive and validation study must be interpreted in the context of its potential limitations. First, this study gives only a first description of the patients' perception of late effects after HSCT. Further research is needed to provide in-depth descriptive analyses concerning differences among age groups, educational strata and how patient characteristics mediate the relation between the BIPQ values and the clinical variables.

Second, we only assessed the German BIPQ's content validity via feedback from clinicians. A patient survey would have yielded a more reliable rating of its content validity as a PRO measurement.

Third, with regard to the small segment of our sample suffering from severe forms of late effects, this sampling bias very likely skewed the validity measurement in relations to other variables. Gathering more knowledge regarding the relationship between clinical and demographic variables and the BIPQ items in HSCT recipients will require further studies. Fourth, this version of the German BIPQ, for use among long-term post-HSCT survivors, asks not about particular illnesses (e.g., cGvHD), but about late effects in general. This general formulation may have made it more difficult for respondents to express their perceptions of specific late effects. Finally, we did not test for reliability. Future studies should explore the German BIPQ's reliability in long-term post-HSCT survivors.

\subsection{Recommendations for clinical practice and future research implications}

Our study showed that the German BIPQ can be easily scored and interpreted, making it particularly useful for clinical applications. However, after its wording has been modified-based on patient cognitive debriefing-further pilot-testing in real-life settings will be necessary to confirm its feasibility and clinical relevance: patient surveys using focus groups or in-depth interviews could help considerably to understand patients' difficulties with the instrument (Basch and Abernethy, 2011; Patrick et al., 2011).

Additionally, further research will be necessary to identify whether these difficulties and misinterpretations could be avoided by replacing the general term "late effects" with a particular late effect, such as cGvHD. Based on these revisions and refinements, the German BIPQ's psychometric properties need to be reassessed in a randomly selected sample of HSCT recipients. Majhail et al.'s descriptive analysis of the BIPQ (2012) reveals that long-lasting late effects are experienced as very stressful. As state-of-the-art followup guidelines suggest, these should be tackled individually in clinical practice (Majhail et al., 2012).

Also, long-term surviving HSCT recipients depend on systematic long-term follow-up to maintain their symptom management and coping strategies (Haggstrom and Doebbeling, 2011). Not only these survivors, but also their spouses and other caregivers exhibit high levels of psychological distress. Therefore, a regular familycentred, symptom-based approach to perceived post-HSCT psychological and physical burdens, i.e., a self-management program focusing on long-term survivors' late effects, should be incorporated into long-term follow-up to identify and manage late effects of cancer and its treatment (Majhail et al., 2012; McCabe et al., 2013). However, provision of self-management support will require funding at the health system level. To date, however, as no appropriate payment system exists for such support in ambulatory HSCT settings, many clinicians have difficulty offering adequate counselling for patients and their families. Ideally, innovative nurse-led programs could include regular nursing counselling, patient and family education with consistent information, and monitoring of treatment side-effects (Armoogum et al., 2013; Kurtin et al., 2013).

\section{Conclusion}

This study has shown that the BIPQ can deepen our knowledge of long-term post-HSCT survivors' perceptions of late effects. Prolonged symptoms were perceived as the most threatening view of late effects. In agreement with previous research, participants indicated that they considered the treatment process itself the most important reason for developing late effects.

All three types of validity were satisfactory for the questionnaire. (1) Our expert survey revealed an acceptable overall content validity, with only three items requiring further refinement; (2) a confirmatory factor analysis showed that the internal structure of the questionnaire fits the underlying construct of the CSM; and (3) strong correlations between individual BIPQ items and clinical variables supported its validity evidence.

Still, before it can be used in long-term post-HSCT survivors, further research is needed to refine the German BIPQ with respect to our results and to re-examine the psychometric properties of the refined version via patient surveys.

\section{Funding}

The PROVIVO study was supported by grants from the Foundation Cancer Research Switzerland (KFS 2705-08-2010) and the 'Stiftung zur Krebsbekämpfung' (2010/280).

\section{Registration number clinicaltrials.gov}

NCT01275534.

\section{Conflict of interest}

None declared.

\section{Acknowledgment}

We gratefully acknowledge our experts for their generous participation in this study and their valuable comments and suggestions for improvements. We would also especially like to thank the Master students of the graduation class 2015 of Nursing Science (INS), University of Basel, for their useful feedback.

\section{References}

AERA, APA, NCME, 2014. Standards for Educational and Psychological Testing. American Educational Research Association, Washington, DC. Arai, S., Arora, M., Wang, T., Spellman, S.R., He, W., Couriel, D.R., Urbano-Ispizua, A., 
Cutler, C.S., Bacigalupo, A.A., Battiwalla, M., 2015. Increasing incidence of chronic graft-versus-host disease in allogeneic transplantation: a report from the Center for International Blood and Marrow Transplant Research. Biol. Blood Marrow Transplant. 21, 266-274.

Armoogum, J., Richardson, A., Armes, J., 2013. A survey of the supportive care needs of informal caregivers of adult bone marrow transplant patients. Support. Care Cancer 21, 977-986.

Basch, E., Abernethy, A.P., 2011. Supporting clinical practice decisions with real-time patient-reported outcomes. J. Clin. Oncol. 29, 954-956.

Beeken, R.J., Eiser, C., Dalley, C., 2011. Health-related quality of life in haematopoietic stem cell transplant survivors: a qualitative study on the role of psychosocial variables and response shifts. Qual. Life Res. 20, 153-160.

Bhatia, S., 2011. Long-term health impacts of hematopoietic stem cell transplantation inform recommendations for follow-up. Expert Rev. Hematol. 4, 437-454.

Bjelland, I., Dahl, A.A., Haug, T.T., Neckelmann, D., 2002. The validity of the Hospital Anxiety and Depression Scale: an updated literature review. J. Psychosomatic Res. 52, 69-77.

Broadbent, E., 2006. The brief illness perception questionnaire scoring instructions.

Broadbent, E., Petrie, K.J., Main, J., Weinman, J., 2006. The brief illness perception questionnaire (BIPQ). J. Psychosomatic Res. 60, 631-637.

Cameron, L., Leventhal, H., 2003. The Self-regulation of Health and Illness Behaviour. Taylor \& Francis Group, London.

Cella, D., Yount, S., Rothrock, N., Gershon, R., Cook, K., Reeve, B.B., Ader, D., Fries, J.F., Bruce, B., Rose, M., 2007. The Patient-Reported Outcomes Measurement Information System (PROMIS): progress of an NIH Roadmap cooperative group during its first two years. Med. Care 45, S3.

Cooke, L., Gemmill, R., Kravits, K., Grant, M., 2009. Psychological consequences of hematopoieitc stem cell transplant. Semin. Oncol. Nurs. 25, 139-150.

De Raaij, E.J., Schroder, C., Maissan, F.J., Pool, J.J., Wittink, H., 2012. Cross-cultural adaptation and measurement properties of the brief illness perception questionnaire-dutch language version. Man. Ther. 17, 330-335.

Fabrigar, L.R., Wegener, D.T., MacCallum, R.C., Strahan, E.J., 1999. Evaluating the use of exploratory factor analysis in psychological research. Psychol. Methods 4, 272.

FDA U.S. Department of Health and Human Services, Center for Drug Evaluation and Researc, Center for Biologics Evaluation and Research \& Center for Devices and Radiological Health Health Qual Life Outcomes, 2006. Guidance for Industry Patient-Reported Outcome Measures: Use in Medical Product Development to Support Labeling Claims, 4, p. 79. http://dx.doi.org/10.1186/1477-7525-4-79.

Ferrara, J.L., Levine, J.E., Reddy, P., Holler, E., 2009. Graft-versus-host disease. Lancet $373,1550-1561$.

Field, A., 2009. Discovering Statistics Using SPSS. Sage publications.

Frost, M.H., Reeve, B.B., Liepa, A.M., Stauffer, J.W., Hays, R.D., 2007. What is sufficient evidence for the reliability and validity of patient-reported outcome measures? Value Health 10, S94-S105.

Gratwohl, A., Baldomero, H., Aljurf, M., Pasquini, M.C., Bouzas, L.F., Yoshimi, A., Szer, J., Lipton, J., Schwendener, A., Gratwohl, M., 2010. Hematopoietic stem cell transplantation. JAMA J. Am. Med. Assoc. 303, 1617-1624.

Gruber, U., Fegg, M., Buchmann, M., Kolb, H., Hiddemann, W., 2003. The long-term psychosocial effects of haematopoetic stem cell transplantation. Eur. J. Cancer Care 12, 249-256.

Hagger, M.S., Orbell, S., 2003. A meta-analytic review of the common-sense model of illness representations. Psychol. Health 18, 141-184.

Haggstrom, D.A., Doebbeling, B.N., 2011. Quality measurement and system change of cancer care delivery. Med. Care 49, S21-S27.

Herzberg, P.Y., Lee, S.J., Heussner, P., Mumm, F.H., Hilgendorf, I., von Harsdorf, S., Hemmati, P., Rieger, K., Greinix, H.T., Freund, M., 2013. Personality influences quality-of-life assessments in adult patients after allogeneic hematopoietic SCT: results from a joint evaluation of the prospective German Multicenter Validation Trial and the Fred Hutchinson Cancer Research Center. Bone Marrow Transplant. 48, 129-134.

Kaiser, H.F., Rice, J., 1974. Little Jiffy, Mark IV. Educational and Psychological Measurement.

Khera, N., Chow, E.J., Leisenring, W.M., Syrjala, K.L., Baker, K.S., Flowers, M.E., Martin, P.J., Lee, S.J., 2011. Factors associated with adherence to preventive care practices among hematopoietic cell transplantation survivors. Biol. Blood Marrow Transplant. 17, 995-1003.

Kirsch, M., Mitchell, S., Dobbels, F., Stussi, G., Basch, E., Halter, J., De Geest, S., 2015. Linguistic and content validation of a German-language PRO-CTCAE-based patient-reported outcomes instrument to evaluate the late effect symptom experience after allogeneic hematopoietic stem cell transplantation. Eur. J. Oncol. Nurs. 19, 66-74. http://dx.doi.org/10.1016/j.ejon.2014.07.007.

Kurtin, S., Lilleby, K., Spong, J., 2013. Caregivers of multiple myeloma survivors. Clin. J. Oncol. Nurs. 17, 25.

Lee, S., Kim, H., Ho, V., Cutler, C., Alyea, E., Soiffer, R., Antin, J., 2006. Quality of life associated with acute and chronic graft-versus-host disease. Bone Marrow Transplant. 38, 305-310.

Lee, S., Vogelsang, G., Flowers, M., 2003. Chronic graft-versus-host disease. Biol. Blood Marrow Transplant. 9, 215-233.

Leventhal, H., Brissette, I., Leventhal, E.A., 2003. The Common-sense model of selfregulation of health and illness. In: Cameron, L., Leventhal, H. (Eds.), The Selfregulation of Health and Illness Behaviour. Taylor \& Francis Group, London, pp. $42-65$.

Leventhal, H., Leventhal, E.A., Contrada, R.J., 1998. Self-regulation, health, and behavior: a perceptual-cognitive approach. Psychol. Health 13, 717-733.

Leventhal, H., Meyer, D., Nerenz, D., 1980. The common sense representation of illness danger. Contributions Med. Psychol. 2, 7-30.

Leventhal, H., Nerenz, D.R., Purse, J., 1984. Illness representations and coping with health threats. In: Baum, A.E., Singer, J.E. (Eds.), Handbook of Psychology and Health. Lawrence Erlbaum Associates, Inc, Hillsdale, NJ, England.

Loberiza, F.R., Rizzo, J.D., Bredeson, C.N., Antin, J.H., Horowitz, M.M., Weeks, J.C., Lee, S.J., 2002. Association of depressive syndrome and early deaths among patients after stem-cell transplantation for malignant diseases. J. Clin. Oncol. 20, 2118-2126.

Majhail, N., Rizzo, J., Lee, S., Aljurf, M., Atsuta, Y., Bonfim, C., Burns, L., Chaudhri, N., Davies, S., Okamoto, S., Seber, A., Socie, G., Szer, J., Van Lint, M., Wingard, J., Tichelli, A., 2012. Recommended screening and preventive practices for longterm survivors after hematopoietic cell transplantation. Bone Marrow Transplant. 47, 337-341.

Majhail, N., Rizzo, J.D., 2013. Surviving the cure: long term followup of hematopoietic cell transplant recipients. Bone Marrow Transplant. 48, 1145-1151.

McCabe, M.S., Bhatia, S., Oeffinger, K.C., Reaman, G.H., Tyne, C., Wollins, D.S., Hudson, M.M., 2013. American Society of Clinical Oncology statement: achieving high-quality cancer survivorship care. J. Clin. Oncol. 31, 631-640.

Mor, V., Laliberte, L., Morris, J.N., Wiemann, M., 1984. The Karnofsky performance status scale: an examination of its reliability and validity in a research setting. Cancer 53, 2002-2007.

Mosher, C.E., Redd, W.H., Rini, C.M., Burkhalter, J.E., DuHamel, K.N., 2009. Physical, psychological, and social sequelae following hematopoietic stem cell transplantation: a review of the literature. Psycho-Oncology 18, 113-127.

Moss-Morris, R., Weinman, J., Petrie, K.J., Horne, R., Cameron, L., Buick, D., 2002. The revised illness perception questionnaire (IPQ-R). Psychol. Health 17, 1-16.

NCI, 2006. Common Terminology Criteria for Adverse Events v3.0 (CTCAE).

Pallua, S., Giesinger, J., Oberguggenberger, A., Kemmler, G., Nachbaur, D., Clausen, J., Kopp, M., Sperner-Unterweger, B., Holzner, B., 2010. Impact of GvHD on quality of life in long-term survivors of haematopoietic transplantation. Bone Marrow Transplant. 45, 1534-1539.

Patrick, D.L., Burke, L.B., Gwaltney, C.J., Leidy, N.K., Martin, M.L., Molsen, E., Ring, L., 2011. Content validity - establishing and reporting the evidence in newly developed patient-reported outcomes (PRO) instruments for medical product evaluation: ISPOR PRO Good Research Practices Task Force report: part 2-assessing respondent understanding. Value Health 14, 978-988.

Pavletic, S.Z., Martin, P., Lee, S.J., Mitchell, S.A., Jacobsohn, D., Cowen, E.W., Turner, M.L., Akpek, G., Gilman, A., McDonald, G., 2006. Measuring therapeutic response in chronic graft-versus-host disease: National Institutes of Health consensus development project on criteria for clinical trials in chronic graftversus-host disease: IV. Response criteria working group report. Biol. Blood Marrow Transplant. 12, 252-266.

Petrie, K.J., Weinman, J., 2012. Patients' perceptions of their illness the dynamo of volition in health care. Curr. Dir. Psychol. Sci. 21, 60-65.

Polit, D.F., Beck, C.T., 2006. The content validity index: are you sure you know what's being reported? Critique and recommendations. Res. Nurs. Health 29, 489-497.

Polit, D.F., Beck, C.T., Owen, S.V., 2007. Is the CVI an acceptable indicator of content validity? Apprais. Recomm. Res. Nurs. Health 30, 459-467.

Rusiewicz, A., DuHamel, K.N., Burkhalter, J., Ostroff, J., Winkel, G., Scigliano, E. Papadopoulos, E., Moskowitz, C., Redd, W., 2008. Psychological distress in longterm survivors of hematopoietic stem cell transplantation. Psycho-Oncology 17, 329-337.

Socié, G., Salooja, N., Cohen, A., Rovelli, A., Carreras, E., Locasciulli, A., Korthof, E., Weis, J., Levy, V., Tichelli, A., 2003. Nonmalignant late effects after allogeneic stem cell transplantation. Blood 101, 3373-3385.

Solber Nes, L., Ehlers, S.L., Patten, C.A., Gastineau, D.A., 2013. Self-regulatory fatigue in hematologic malignancies: impact on Quality of Life, Coping, and adherence to medical recommendations. Int. J. Behav. Med. 20, 13-21.

Sorror, M.L., Storer, B.E., Sandmaier, B.M., Maris, M., Shizuru, J., Maziarz, R., Agura, E., Chauncey, T.R., Pulsipher, M.A., McSweeney, P.A., Wade, J.C., Bruno, B., Langston, A., Radich, J., Niederwieser, D., Blume, K.G., Storb, R., Maloney, D.G., 2008. Five-year follow-up of patients with advanced chronic lymphocytic leukemia treated with allogeneic hematopoietic cell transplantation after nonmyeloablative conditioning. J. Clin. Oncol. 26, 4912-4920.

Sprangers, M.A., Schwartz, C.E., 1999. Integrating response shift into health-related quality of life research: a theoretical model. Soc. Sci. Med. 48, 1507-1515.

Stein, K.D., Syrjala, K.L., Andrykowski, M.A., 2008. Physical and psychological longterm and late effects of cancer. Cancer 112, 2577-2592.

Syrjala, K.L., Langer, S.L., Abrams, J.R., Storer, B., Sanders, J.E., Flowers, M.E. Martin, P., 2004. Recovery and long-term function after hematopoietic cell transplantation for leukemia or lymphoma. JAMA J. Am. Med. Assoc. 291, 2335-2343.

Syrjala, K.L., Langer, S.L., Abrams, J.R., Storer, B.E., Martin, P.J., 2005. Late effects of hematopoietic cell transplantation among 10-year adult survivors compared with case-matched controls. J. Clin. Oncol. 23, 6596-6606.

Tichelli, A., Rovo, A., Socie, G., 2012. Late effects after hematopoietic stem cell transplantation-critical issues. Curr. Probl. Dermatol. 43, 132-149.

Van Oort, L., Schroder, C., French, D.P., 2011. What do people think about when they answer the Brief Illness Perception Questionnaire? A 'think-aloud' study. Br. J. Health Psychol. 16, 231-245.

Weinman, J., Petrie, K.J., Moss-Morris, R., Broadbent, E., Sivertsen, B., 2012. The Brief-IPQ Translation. Retrieved from: http://www.uib.no/ipq/index.html.

Weinman, J., Petrie, K.J., Moss-Morris, R., Horne, R., 1996. The illness perception 
questionnaire: a new method for assessing the cognitive representation of illness. Psychol. Health 11, 431-445.

Xiao, C., Polomano, R., Watkins Bruner, D., 2013. Comparison between patientreported and clinician-observed symptoms in oncology. Cancer Nursing 36, E1-E16.
Zigmond, A.S., Snaith, R.P., 1983. The hospital anxiety and depression scale. Acta Psychiatr. Scand. 67, 361-370.

Zivkovic, M.V., Dediol, I., Ljubicic, I., Situm, M., 2012. Sun behaviour patterns and perception of illness among melanoma patients. J. Eur. Acad. Dermatol. Venereol. 26, 724-729. 